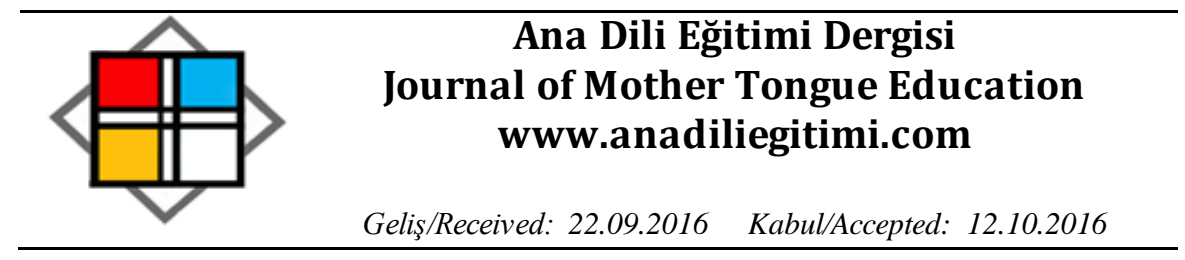

\title{
Temel Seviyede Yabancı Dil Olarak Türkçe Öğretiminde Çizgi Romanların Öğrenme Düzeyine Etkisi*
}

\author{
Aliye USLU ÜSTTEN ${ }^{1}$ \\ Salim PILAV ${ }^{2}$
}

\begin{abstract}
Öz
Öğrenme biçimlerindeki farklılık, eğitim uygula malarında; özell likle de dil öğretiminde çoklu eğitim ortamlarını âdeta zorunlu kılmaktadır. Sadece ders kitabı aracıl Ĭıyla gerç ekleşti rilmeye çalışılan eğitim-öğretim, hedef kitlenin belli bir süre sonra sıkılmasına sebebiyet vermekte ve yeni öğrenmeler için bir motivasyon unsuru ol maktan uzak kalmaktadır. Bu yüzden hem ders kitabına yardımcı hem de öğrenmeyi daha zevkli, daha anla mlı ve daha kalıcı hâle getirici unsurlara ihtiyaç duyulmaktadır. Bu unsurların başında çizgi romanlar gelmektedir. Çizgi roman, diğer yazın türlerinden farklı olarak okurun ihtiyaçlarına göre şekillenen ürünlerdir. Resimle metnin iç içe geçtiği bu tür, dil öğretiminde özellikle okuma-anlama becerisine katkı sağlayan önemli bir araçtır. Diğer metin türleri gibi çizgi romanlar da yabancı dil öğretiminde çok farklı yönleriyle kullanılabilir. Çizgi romanlar, özellikle A1 ve A2 seviyelerinde günlük dil kalıplarını öğrenme konusunda öğrencilere kolaylık sağlayabilir. Bu çalışmada yabancılara Türkçe öğretiminde çizgi romanların kullanımının etkisi üzerinde durulacaktır. Araştırma, Kırıkkale Üniversitesi ve Gazi Üniversitesi Türkçe Öğretim Merkezlerinde A1 ve A2 seviyesindeki öğrenciler kapsamında gerçekleştirilmiştir. Örnekleme yönteminin uygulandığı çalışmada veriler, araştırmacılar tarafından geliştirilen "Anlama Becerisi Ölçme Aracı" ile elde edilmiştir. Buna göre, çizgi romanların okuduğunu anlama becerisinin kavrama basamağının geliştirilmesinde düz metinlere göre daha etkili olduğu tespit edilmiştir.
\end{abstract}

Anahtar Kelimeler: yabancı dil olarak Türkçe öğretimi, çizgi roman, okuma-anlama, eğitsel araç

\section{The Effect of Comics on Learning at Beginner Level in Teaching Turkish as a Foreign Language}

\begin{abstract}
Differences in learning styles make it necessary to use multi-media teaching environments in education, especially, in foreign language teaching. Education which is sought to be realized through the course book only causes audience to get bored after some time and falls short of providing motivation for further learning. Therefore, there is need for elements that are both auxiliary to course books and help make learning more pleasant, more meaningful, and more permanent. Comics are one of first few that come to mind in this regard. Unlike other genres, comics are materials that are shaped according to the needs of readers. This genre, in which
\end{abstract}

\footnotetext{
* Bu çalışma Yunus Emre Enstitüsü ve Türk Dil Kurumu işbirliğinde gerçekleştirilen “Uluslararası Türkçenin Yabancı Dil Olarak Öğretimi Sempozyumu"nda sunulan bildirinin genişl etilmiş hâlidir.

1 Doç. Dr., Gazi Üniversitesi Türk Dili Bölümü, Gazi Üniversitesi Türkçe Öğretim Merkezi (TÖMER). Maltepe, Ankara.aliyeuslu@yahoo.com

2 Yrd. Doç Dr., Kırıkkale Üniversitesi Eğitim Fakültesi, Türkçe Eğitim Bölümü, Kırıkkale. spilav@kku.edu.tr
} 
pictures intertwine with the text, is an important tool in language teaching, which especially contributes to the reading comprehension skill. Like other types of texts, comics can be used in many different aspects of foreign language teaching. Comics may provide students with ease in learning the patterns of daily language, especially at A1 and A2 levels. This article focus es on the effect of the use of comics in teaching Turkish to foreigners. The study was conducted with A1 and $A 2$ level students at the Turkish Teaching Centers of Kırıkkale University and Gazi University. The data, gained through the implementation of the sampling method, were obtained using the "Comprehension Skills Assessment Tool" developed by the researchers. Based on the data, it was found that comics were more effective on the development of reading comprehension skills than regular texts.

Keywords: teaching Turkish as a foreign language, comics, rea ding comprehension, educational tool

\section{Giriş}

Yaşadığımız çağ, görsel unsurların özellikle medya aracılı̆ıyla ön plana çıktığı, her alanda ve her anlamda öğrenmenin bu görsellik sayesinde daha etkili ve kalıcı olduğu bir çağdır. Öğrenme biçimlerindeki farklı ık, eğitim uygulamalarında; özellikle de dil öğretiminde çoklu eğitim ortamlarını âdeta zorunlu kılmaktadır. Bu çerçevede, eğitsel araç ve gereçler öğrenme ortamını bir taraftan farklılaştırıp zenginleştirirken diğer taraftan da öğrenmenin daha zevkli ve daha anlamlı hâle gelmesini sağlayacaktır. Sadece ders kitabı aracılığıyla gerçekleştirilmeye çalışılan eğitim öğretim hedef kitlenin belli bir süre sonra sıkılmasına sebebiyet vermekte ve yeni öğrenmeler için bir motivasyon unsuru olmaktan uzak kalmaktadır. Bu yüzden bir taraftan ders kitabına yardımcı, diğer taraftan da öğrenmeyi daha zevkli, daha anlamlı ve daha kalıı hâle getirici unsurlara ihtiyaç duyulmaktadır. Dile ait kelimelerin, günlük ifade kalıplarının öğretimin de yine günlük hayatın içinden alınmış gerçek örneklerin yer aldığı çeşitli materyaller kullanılabilir (Doğan, 2014, 93). Bu unsurların arasında çizgi romanlar bulunmaktadır. Çizgi romanlar, resimle metnin iç içe geçtiği, dil öğretiminde özellikle okuma-anlama becerisine katkı sağlayan son derece önemli bir araçtır. Diğer metin türleri gibi çizgi romanlar da yabancı dil öğretiminde çok farklı yönleriyle kullanılabilir. Çizgi romanlar, özellikle A1 ve A2 seviyelerinde günlük dil kalıplarını öğrenme konusunda öğrencilere kolaylık sağlayabilir.

Insanların doğayı taklit etmesiyle ortaya çıkan çizgi roman, zaman içinde resim ve metnin bir arada kullanılarak duygu ve düşüncelerin ifade ediliş biçimi hâline gelmiştir. Romanın "yozlaşmış" şekli aynızamanda yaratıı ve çarpıcı ayrımlarıyla yazın türleri arasında özgün bir yere sahip olmuştur (Cantek, 2002: 28).

Çizgi romanların genel olarak taşıdığı özellikler şunlardır: 
1. Çizgi roman görselleri, belirli bir hikâyeyi anlatır.

2. Diyalog, hareket, duygu ve düşünce, yer ve zaman, neden-sonuç ilişkileri gibi kurgu unsurları resim ve çizimlerle ifade edilir.

3. Karakterler, birbirini tekrarlayan özelliklere sahiptir.

4. Art arda gelen birçok olay veya durum, birbiriyle ilişkili karel erin kısa bir zaman akışına sığdırılmasıyla verilir (Uslu Üstten, 2014: 195).

Çizgi romanın gelişimi ilk olarak 1800'lerde Fransa ve Belçika'da gelişmeye başlar. 1920'li yıllarda yayımlanan Tintin (TenTen), bu alanda önemli bir başarı elde eden çizgi romanlardır. Tintin, Asterix, Lucky Luke (Red Kit) ve Les Schtroumpfs (Şirinler), birçok dile çevrilerek farklı ülkelerde de tanınmıştır. İspanya' da 1930'lu yıllarda çizgi roman sahasında çok sayıda eser verildiği görülür. Ancak 1980'lere gelindiğinde Amerikan yayınlarının etkisi görülmeye başlar. İngiltere'de de çizgi roman, Amerikan yayınlarının etkisi altında gelişmiştir. Almanya ise savaş sonrası ortaya çıkan sosyal ve ekonomik şartlar nedeniyle çizgi roman alanında geri kalır. Türkiye'de çizgi roman ilk olarak resimli çocuk dergilerinde görülür ancak özel bir alan değildir. Bu dönemde Cemal Nadir Güler'in 1929'da çizmeye başladığı Amcabey tiplemesi önemlidir (Ömer Seyfettin, 1924).

1930'lu yıllardan sonra Amerikan çizgi romanları tercüme isimlerle yayımlanmaya başlanır. Bunun yanı sıra millî konuların işlendiği çizgi romanlar da tasarlanır. 1945'te yayımlanan Doğan Kardeş adlı çocuk dergisi, Tommiks adıyla uyarlanan Capitan Miki adlı İtalyan kovboy çizgi romanı (Cantek, 2002: 26), sonraki dönemde Turhan Selçuk'un Abdülcanbaz, Oğuz Aral'ın Hafiyesi Mahmut (1956), Utanmaz Adam (1959) ve Avanak Avni (1973)'si kahramanlarıyla bir dönemin geniş okur kitlelerine ulaşan çizgi romanlardır. Abdullah Ziya Kozanoğlu'nun Karaoğlan (1959) serileri, hem yetişkinlerin hem de gençlerin takip ettiği tarihî çizgi romanlardır. İtalyan çizgi romanlarından /I Commandante Mark, Kaptan Swing adıyla; Ken Parker, Alaska adıyla Türkçeye çevrilmiş ve yayımlanmıştır.

Günümüzde yabancı kaynaklı çizgi romanların yanı sıra, Türk ve dünya klasiklerinin çizgi romana uyarlandıkları görülmektedir. Böylece bu eserlerin daha çok kesim tarafından okunmasını sağlanmakta, farklı milletlerden ve kültürlerden insanların eserleri tanıma fırsatı doğmaktadır. Bununla birlikte çizgi romanların roman dünyasıyla birleştirilmesi konusunda farklı görüşler ortaya çıkmıştır. Ünlü eserlerin çizgi roman olarak yayımlanmasıyla eserlerin gerçek anlamda okunmuş sayılmayacağı görüşünü ileri sürenler de bulunmaktadır. Ancak tüm dünyada tanınmış eserlerin çizgi roman uyarlamaları yabancılara Türkçe öğretiminde kolaylık sağlayacağından B1 ve ileri düzeylerde bu romanları okutmak faydalı olacaktır.

Çizgi romanlar tür özellikleri açısından resim ve metnin bir arada olması sebebiyle takip edilmesi kolay bir kurguya sahiptir. Uzun hikâyelere kıyasla daha kısa sürede okunabilme özelliği, çizgi 
romanların yabancı öğrencilerin uzun hikâyelere karşı duydukları ön yargıyı kırmada bir basamak olarak kullanılabilir. Aynı zamanda görsellerdeki evrensellik, çizgi romanları farklı milletlerin ortak buluşma noktası hâline getirir. Böylece değişik kültür unsurlarını tanıtmada da bir araç olarak kullanılabilir.

\section{Çizgi Romanlardan Yararlanarak Dil Becerilerinin Geliştirilmesi}

Çizgi romanda diyalog ve görsellerin bir arada kullanımı öncelikle anlamayı, dolayısıyla okuma ve dinlemeyi kolaylaştıran bir unsurdur. Bunun yanı sıra diyaloglar anlatma becerilerini geliştirmede bir araç olarak kullanılabilir. Çizgi romanlarla geliştirilebilecek dil becerileri aşağıda daha ayrıntılı bir şekilde açıklanmaktadır:

1. Okuma: Öğrencilerin kelime hazinelerinin zenginleştirilmesinde ve okuma becerilerinin geliştirilmesinde çizgi romanlar görsellerin ön plana çıkması sebebiyle önemli bir etkiye sahiptir. Avrupa Dilleri Öğretimi Ortak Çerçeve Programı (Common European Framework, 2001)ders kitabı ve yardımcı materyal yazarlarına genel standart önermektedir (Deniz ve Uysal, 2010: 243). Bu amaçla her seviyede öğretilmesi gereken bilgilerin yer aldığı Çerçeve metne göre hazırlanan çizgi romanlar aracıl Ĭ̆ ile öğrencileryeni kelimelerle buluşturulurve özellikle duygu durumları gibi soyut ifadelerin anlaşılmasını kolaylaştırır. Böylece hem A1 seviyesinde öğrenilen ve ileriki seviyelerde de kullanılabilecek kelimelere değinilir hem de öğrencilerin metnin dünyasındaki karakterlerle bütünleşmeleri sağlanır.

Çizgi roman, sadece metni okuma ve görselleri fark etme değildir, farklı becerileri harekete geçiren bir araçtır. Çizgi romanı tam ve doğru anlayabilmek için görsel ve metni ilişkilendirerek anlamı yakalamak gerekir. Bu da, okuyucunun metinle birlikte görsellere de yoğunlaşmasını ve cümlelerle görselleri bütünleştirmesini sağlar. Böylece ifadelerde geçen sembolleri, mecazları, komik anlamları ve günlük dilde kullandığımız ancak yazı dilinde bulunmayan anlamaları kolaylaştııı. Yazı ve görselin bir arada sunulmasıyla bağlamdan hareketle kelime öğrenimi kolaylaşır.

2. Yazma: Çizgi romanlar öğrencilerin yazma becerilerinin geliştirilmesinde örnek metin olması bakımından güçlü bir etkiye sahiptir. Çizgi romanda anlatılan birbirinden farklı olay, duygu, düşünce ve hayaller öğrencilerin yaratıcılığını artıır. Hikâye kurgu mantığını anlamaları ve olayın devamını takip edebilme becerileri gelişir. A1 seviyesinde kısa diyaloglar yazdırılarak başlanan yazma çalışmaları, daha sonraki seviyelerde uzun metinler yazmalarını kolaylaştıracaktır.

3. Konuşma ve Dinleme: Çizgi romanlar Türkçenin öğretilmesinde kullanılması konuşma ve dinleme becerilerini olumlu yönde etkiler. Görsele dayalı anlatım, sesli okuma, drama, rol yapma ve tartışma gibi etkinlikler her iki beceriyi birden geliştirir. Temel düzeyde telaffuz çalışmalarında etkili bir araçtır. 
4. Dil Bilgisi: Dil bilgisi öğretiminde birçok kuralın cümlenin bağlamından hareketle kavratılması için çizgi romanlar kolaylık sağlayan metinlerdir. Dolaylı ve doğrudan anlatım, kipler gibi konuların anlatımında çizgi romanlardan faydalanılabilir.

\section{Yöntem}

\section{Araştırmanın Modeli}

Bu çalışma betimsel niteliktedir. Araştırmada tarama modeline dayalı örnekleme yöntemi kullanılmıştır. Tarama modelleri geçmişte veya hâlen var olan bir durumu var olduğu şekliyle betimlemeyi amaçlayan yaklaşımdır (Karasar, 2015). Bu yaklaşıma göre evren hakkında genel bir yargıya varmak amacı ile evrenin tümü veya evrenden alınacak bir grup örnek üzerinde tarama yapııır. Tabakalı örneklem, evrendeki alt grupların örneklemde temsil edilmelerinin garanti altına alındığı örneklemdir. Bu yöntemle, küçük örneklemler aracılığıyla daha temsilî istatistiklere ulaşılmakta ve alt gruplar arasında karşılaştırma yapmak kolaylaşmaktadır (Balcı, 2001).

\section{Evren ve Örneklem}

Araştırma, Kırıkkale Üniversitesi ve Gazi Üniversitesi Türkçe Öğretim Merkezlerinde A1 ve A2 seviyesinde 75’er öğrenci olmak üzere toplam 150 öğrenci kapsamında gerçekleştirilmiştir.

\section{Veri Toplama ve Analizi}

Uygulamada kullanılan ve araştırmacılar tarafından kurgulanan anlama metni, hem düz metin hem de çizgi roman metni olarak iki farklı öğrenci grubuna okutulmuştur. Uygulamada kullandığımız çizgi roman örneği, A1 temel düzeye yönelik hazırlanmış, kişisel ve kamusal alana yönelik günlük konuşmalara dayalı diyaloglardan oluşmaktadır.

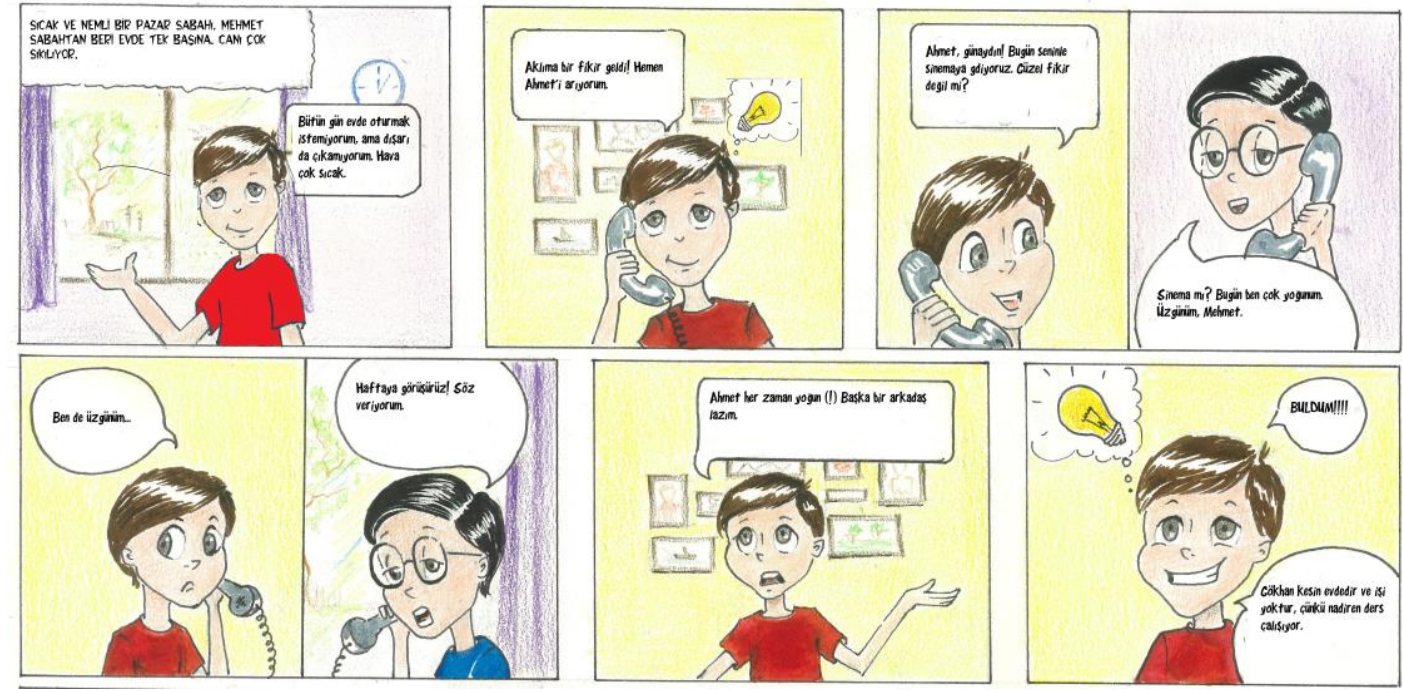

Figür 1 
Çizgi romanda, arkadaşlarıyla vakit geçirmek isteyen Mehmet'in bir türlü kendisine arkadaş bulamaması ve yalnız başına eğlenmek zorunda kalışı anlatılmaktadır.

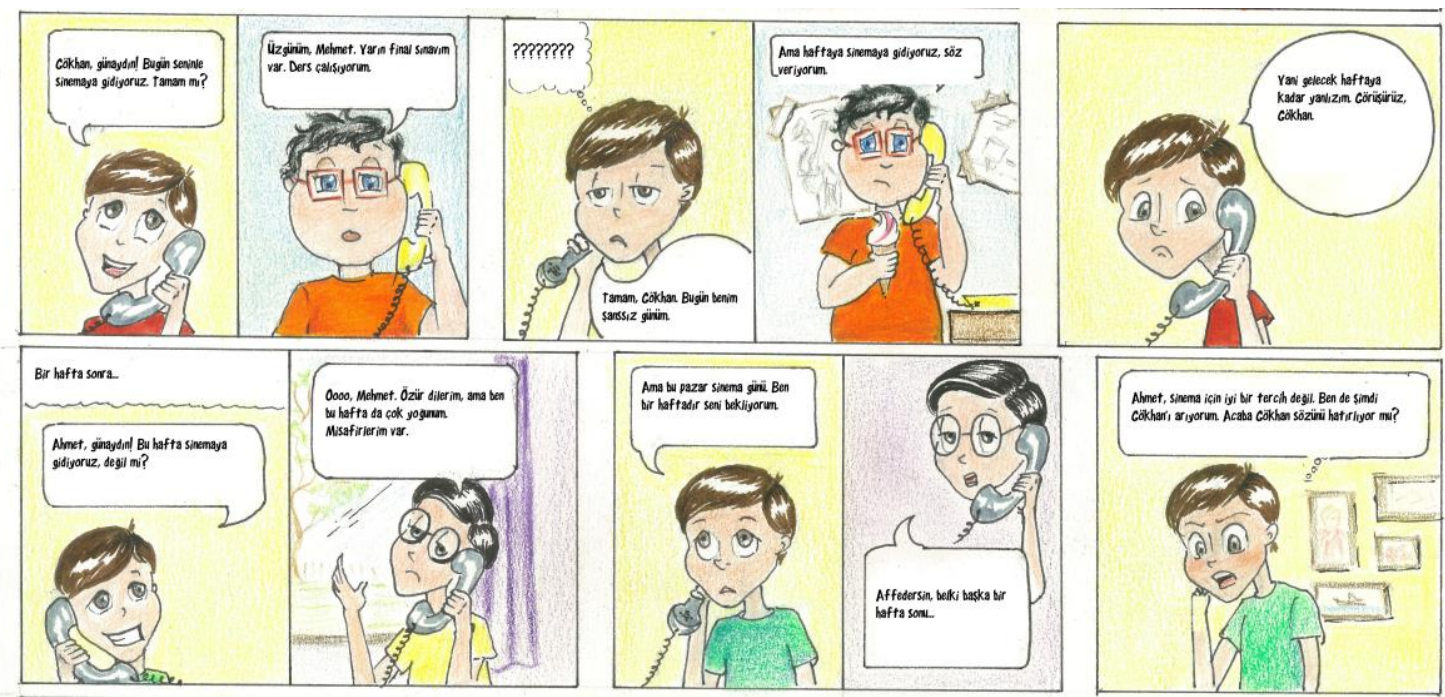

Figür 2

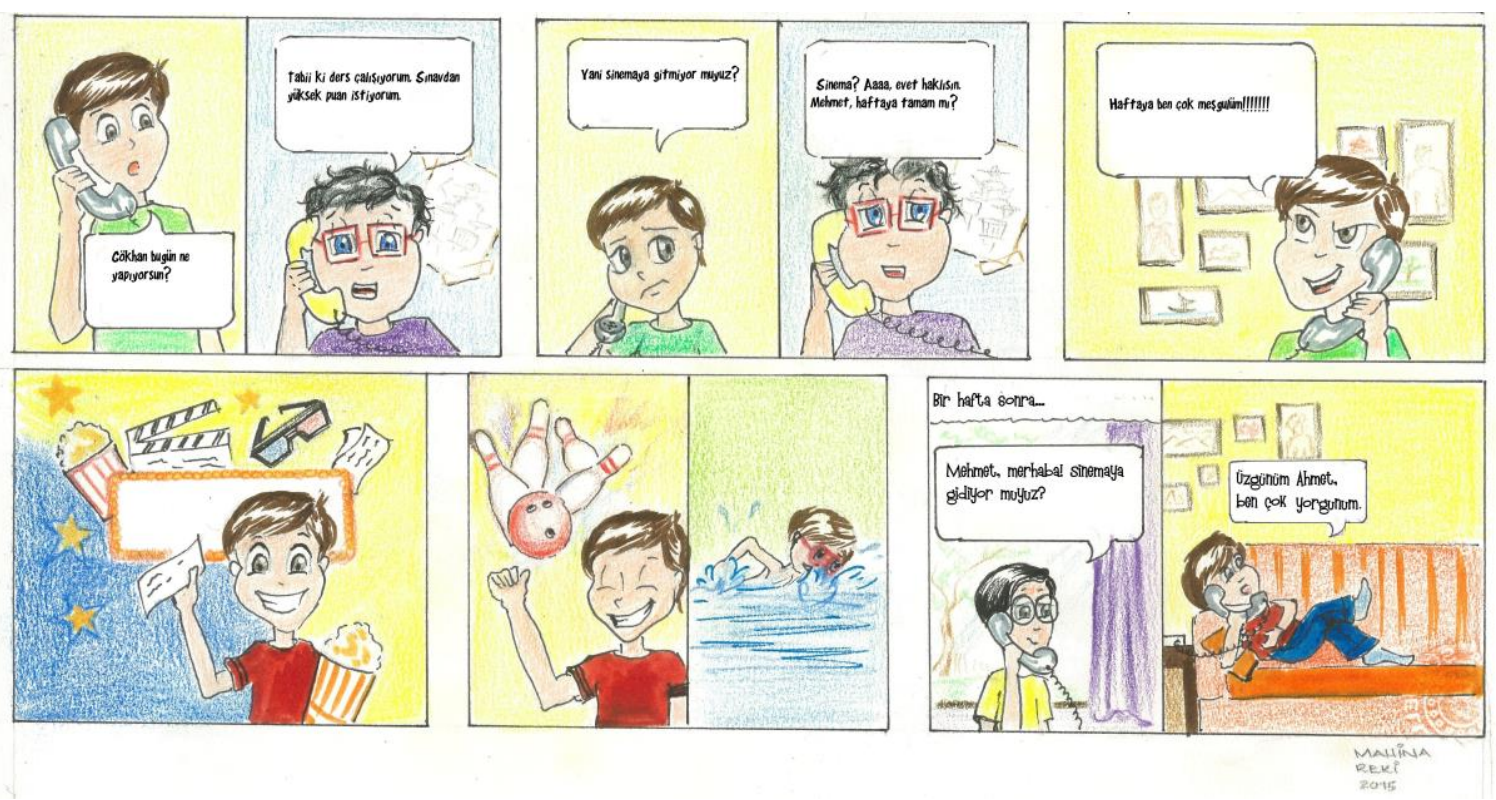

Figür 3

Çalışma verileri, araştırmacılar tarafından geliştirilen "Anlama Becerisi Ölçme Aracı" ile elde edilmiştir. "Anlama Becerisi Ölçme Aracı"nda doğru-yanlış ve çoktan seçmeli olmak üzere iki farklı soru tipinde toplam 15 soru sorulmuştur. Sorular, üç alan uzmanı tarafından değerlendirildikten sonra uygulanmıştır. Elde edilen verilere betimsel istatistik yöntemlerinden olan frekans analizi uygulanmıştır. Sonuçlar içerik analizi yöntemiyle incelenmiştir. 


\section{Bulgular ve Yorum}

Tablo 1: Cevapların Cinsiyete Göre Durumuna Yönelik Bulgular

\begin{tabular}{|c|c|c|c|c|c|c|c|c|}
\hline \multirow[t]{3}{*}{$\begin{array}{l}\text { Soru } \\
\text { Numarası }\end{array}$} & \multicolumn{4}{|c|}{$\begin{array}{l}\text { Çizgi roman okuyan öğrencilerin } \\
\text { doğru cevap frekans ve yüzdesi }\end{array}$} & \multicolumn{4}{|c|}{$\begin{array}{l}\text { Düz metin okuyan öğrencilerin } \\
\text { doğru cevap frekans ve yüzdesi }\end{array}$} \\
\hline & \multicolumn{2}{|c|}{$\mathrm{KIz}$} & \multicolumn{2}{|c|}{ Erkek } & \multicolumn{2}{|c|}{$\mathrm{K} \mathrm{IZ}$} & \multicolumn{2}{|c|}{ Erkek } \\
\hline & $N$ & $\%$ & $\mathrm{~N}$ & $\%$ & $\mathrm{~N}$ & $\%$ & $\mathrm{~N}$ & $\%$ \\
\hline 1. soru & 30 & 40 & 16 & 21,3 & 21 & 28 & 12 & 16 \\
\hline 2. soru & 38 & 50,6 & 20 & 26,6 & 28 & 37,3 & 10 & 13,3 \\
\hline 3. soru & 22 & 29,3 & 18 & 24 & 9 & 12 & 7 & 9,3 \\
\hline 4. soru & 19 & 25,3 & 35 & 46,6 & 9 & 12 & 21 & 28 \\
\hline 5. soru & 18 & 24 & 30 & 40 & 19 & 25,3 & 7 & 9,3 \\
\hline 6. soru & 28 & 37,3 & 20 & 26,6 & 23 & 30,6 & 11 & 14,6 \\
\hline 7. soru & 35 & 46,6 & 25 & 33,3 & 12 & 16 & 8 & 10,6 \\
\hline 8. soru & 40 & 53,3 & 20 & 26,6 & 20 & 26,6 & 18 & 24 \\
\hline 9. soru & 38 & 50,6 & 10 & 50,6 & 22 & 29,3 & 24 & 32 \\
\hline 10. soru & 18 & 24 & 18 & 24 & 14 & 18,6 & 16 & 21,3 \\
\hline 11. soru & 38 & 50,6 & 20 & 26,6 & 29 & 38,6 & 9 & 12 \\
\hline 12. soru & 24 & 32 & 14 & 18,6 & 11 & 14,6 & 17 & 22,6 \\
\hline 13. soru & 20 & 26,6 & 38 & 50,6 & 8 & 10,6 & 22 & 29,3 \\
\hline 14. soru & 19 & 25,3 & 15 & 20 & 13 & 17,3 & 25 & 33,3 \\
\hline 15. soru & 14 & 18,6 & 22 & 29,3 & 12 & 16 & 8 & 10,6 \\
\hline
\end{tabular}

Tablo 1'deki verilere göre her iki grupta da kı öğrencilerin erkek öğrencilere göre sorulara doğru cevap verme oranı daha yüksektir. Kız öğrencilerden çizgi roman okuyan grupta yer alanlar tarafından en fazla doğru cevaplanan 8. sorudur (\% 53,3). Düz metin okuyan kız öğrenciler ise çoktan seçmeli soru olan 11 . soruyu en yüksek oranda $(\% 38,6)$ cevaplamışlardır.

Tablo 2: Öğrencilerin Metni Anlama Düzeylerine Yönelik Bulgular

\begin{tabular}{|c|c|c|c|c|}
\hline \multirow[t]{2}{*}{$\begin{array}{l}\text { Soru } \\
\text { Numarası }\end{array}$} & \multirow{2}{*}{$\begin{array}{l}\text { Çizgi roman } \\
\text { öğrencilerin doğru } \\
\text { frekans ve yüzdesi } \\
\mathrm{N}\end{array}$} & \multirow{2}{*}{$\begin{array}{r}\text { okuyan } \\
\text { cevap } \\
\%\end{array}$} & \multicolumn{2}{|c|}{$\begin{array}{l}\text { Düz metin okuyan öğrencilerin } \\
\text { doğru cevap frekans ve yüzdesi }\end{array}$} \\
\hline & & & $\mathrm{N}$ & $\%$ \\
\hline 1. soru & 46 & 61,3 & 33 & 44 \\
\hline 2. soru & 58 & 77,3 & 38 & 50,6 \\
\hline 3. soru & 40 & 53,3 & 16 & 21,3 \\
\hline 4. soru & 54 & 72 & 38 & 50,6 \\
\hline 5. soru & 48 & 64 & 26 & 34,6 \\
\hline 6. soru & 48 & 64 & 34 & 45,3 \\
\hline 7. soru & 60 & 80 & 20 & 26,6 \\
\hline 8. soru & 60 & 80 & 38 & 50,6 \\
\hline 9. soru & 48 & 64 & 46 & 61,3 \\
\hline 10. soru & 36 & 48 & 30 & 40 \\
\hline 11. soru & 58 & 77,3 & 38 & 50,6 \\
\hline 12. soru & 34 & 45,3 & 28 & 37,3 \\
\hline 13. soru & 58 & 77,3 & 30 & 40 \\
\hline 14. soru & 34 & 45,3 & 38 & 50,6 \\
\hline 15. soru & 46 & 61,3 & 20 & 26,6 \\
\hline
\end{tabular}


Öğrencilerin sorulara verdikleri cevaplar incelendiğinde metni çizgi roman tü ründe okuyan öğrencilerin anlama ve kavramaya yönelik doğru-yanlış sorularınıyüksek oranda doğru cevapladıkları görülmüştür. Buna karşılık düz metni okuduktan sonra doğru cevap veren öğrencilerin oranı diğer gruba göre daha düşüktür. Sebep-sonuç anlamı içeren soruların doğru cevaplanma oranı incelediğinde de çizgi roman okuyan öğrencilerin düz metin okuyan öğrencilere göre daha başarılı oldukları tespit edilmiştir. Buna göre metni görsel unsurlarla birlikte okuyan öğrencilerin metni anlama düzeylerinde anlamlı bir farklılık olduğu görülmüştür.

\section{Sonuç}

Yabancılara Türkçe öğretiminde ders kitabının yanında birçok araçtan faydalanmak mümkündür. Çizgi romanların görselliği ön plana çıkaran, olaylarıve durumları kısa ifadelerle aktaran özelliği Türkçe öğrenen yabancı öğrencilerin metnin kurgusunu anlamalarını kolaylaştırmaktadır. Araştırma sonuçları da bu yönde anlamlı farklıı ık olduğunu göstermektedir. Çizgi romanların diğer bir özelliği de hareketli kurgusu ve kahramanlarının sahip olduğu olumlu özellikleridir. Bu bakımdan okuyucu üzerinde olumlu etki bırakan eserler olması sebebiyle Türkçe öğretiminde her seviyede faydalanılabilecek türler arasındadır. Günümüzde eğitimde çizgi roman ve çizgi roman tekniklerinin kullanılması yaygınlaşırken, dil öğretiminde de etkili bir araç olarak katkılar sağlayacaktır. Dil becerilerinin geliştirilmesinin yanında hayal gücünü zenginleştirmede de etkilidir. Dersteöğretilen dil kalıplarıyla çizgi romanlarda karşılaşan öğrenciler, dersle metinler arasında bağlantı kurmuş olacaklardır. Bu tür uygulamalar, yabancılara Türkçe öğretiminde dil öğrenimini etkili ve kalııı hâle getirmede katkı sağlayacaktır.

\section{Kaynaklar}

Balcı, A. (2001). Sosyal bilimlerde araştırma. Ankara: Pegem A.

Cantek, L. (2002). Türkiye'de çizgi roman. İstanbul: İletişim Yayıncılık.

CEFR (Common European Framework References) (2002). Common Eurpean framework of reference for languages: learning, teaching, assessment case studies, Council of Europe: Strasbourg.

Deniz, K., Uysal, B. (2010). Avrupa dilleri öğretimi ortak çerçeve metni ve yurt dışındaki Türk çocukları için Türkçe ve Türk kültürü öğretim programı. TÜBAR, XXVII: 239-261.

Doğan Kardeş Dergisi (1945). İstanbul: Yapı Kredi Yayınları.

Doğan, Y. (2014). Yabancılara Türkçe kelime öğretiminde market broşürlerinden yararlanma. Journal of Language and Linguistic Studies, 10 (1), 89-98.

Karasar, N. (2015). Bilimsel araştırma yöntemi. Ankara: Nobel Yayın Dağıtım.

Ömer Seyfettin. (1924). Resimli dünya dergisi.

Uslu Üstten, A. (2014). Gençlik edebiyatı. Ankara: Grafiker Yayınları. 